\title{
Experimental and computational investigation with Hirshfeld surface analysis of bis(glycine) strontium dichloride trihydrate
}

\author{
ANBARASAN RADHAKRISHNAN ${ }^{1}$, ANNA LAKSHMi MUPPUDATHI ${ }^{2}$, KALYANA SundAR \\ JEYAPERUMAL ${ }^{1, *}$ \\ ${ }^{1}$ Materials Science Laboratory, Department of Physics, Periyar University, Salem, Tamil Nadu-636011, India \\ ${ }^{2}$ Department of Physics, ERK College of Arts and Science, Dharmapuri, Tamil Nadu-636905, India
}

\begin{abstract}
Good-quality semiorganic single crystals of bis(glycine) strontium dichloride trihydrate (GSC) were grown by slow evaporation technique. The lattice parameters of the grown crystal were verified through single crystal X-ray diffraction. Besides, the crystallinity of the material was analyzed with powder X-ray diffraction. The fingerprint of functional groups of this material was analyzed by FT-IR technique. The UV transparency cutoff wavelength of GSC was found to be $240 \mathrm{~nm}$ and the crystal exhibited $80 \%$ transmission in the entire visible region. All intermolecular and intramolecular interactions of the grown crystal were interpreted by Hirshfeld surface analysis, and the strength of the interactions was graphically illustrated by fingerprint graphs. The intramolecular charge transfers of the crystal were assessed through frontier molecular orbital analysis.
\end{abstract}

Keywords: glycine; molecular interactions; semiorganic crystal; Hirshfeld surface analysis; first order hyperpolarizability

\section{Introduction}

Nonlinear optical materials occupy a crucial position in modern technology because of their use in optical communication, optical data storage, and laser applications [1, 2]. The organic materials have high nonlinear susceptibilities but in industrial applications the material exhibits low optical transparency and low thermal stability. On the other hand, inorganic materials are widely used in industrial applications because of their good optical transparency and high thermal and mechanical stability, despite the low nonlinear susceptibility [3]. The drawbacks of organic and inorganic materials may be overcome by semiorganic materials. Subsequently, by incorporation of organic and inorganic compounds, it is possible to obtain a semiorganic material possessing integrated properties. Glycine is the simplest amino acid having one carboxyl group, one amino group and two hydrogens. Moreover, glycine is a nonchiral compound. Many studies

*E-mail: jksundar50@gmail.com have been carried out on glycine based nonlinear optical materials $[4,5]$. The density functional theory is the most frequently used to predict the molecular properties of metal organic compounds.

Coordination compounds of glycine with transition metal halogen ions form a group of nonlinear optical materials, such as dichloro-diglycine zinc, dichloro-diglycine barium, diglycine manganese chloride, diglycine hydrochloride and glycine lithium chloride [6-12]. In our study, we have prepared a metal halogenate crystal of bis(glycine)strontium dichloride trihydrate (GSC) crystal for optoelectronic applications. In the following sections, synthesis, crystal growth, vibrational analysis, optical studies, Hirshfeld surface analysis, frontier molecular orbital analysis and NLO activity have been reported.

\section{Experimental}

\subsection{Synthesis and crystal growth}

Bis(glycine) strontium dichloride trihydrate crystal was synthesized from stoichiometric 
amounts of glycine (Merck) and strontium chloride hexahydrate in the ratio $2: 1$ using double distilled water as a solvent. The mixture was stirred at room temperature for six hours, and the final compound was attained as a homogeneous solution. The solution was then evaporated at room temperature, and the purity of the synthesized salt was enhanced by repeated recrystallization. After the period of 15 days, well-defined transparent crystals were harvested. The photograph of the grown crystal is shown in Fig. 1.

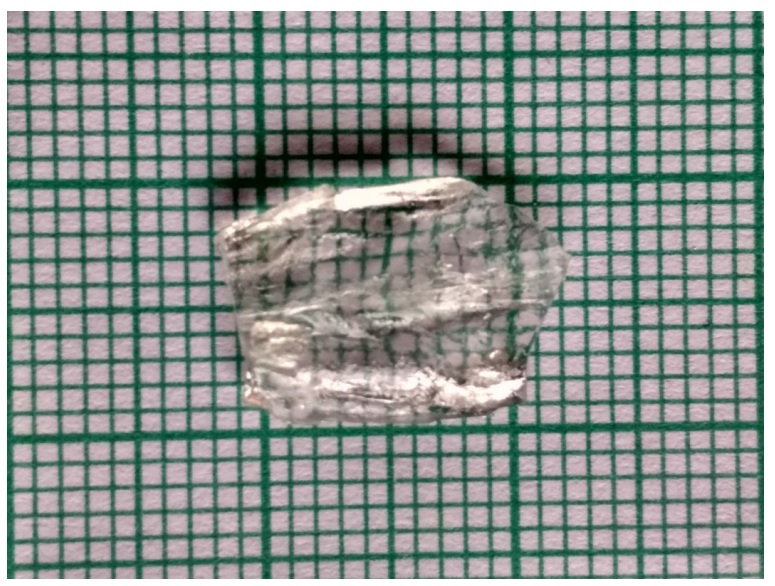

Fig. 1. Photograph of as-grown crystal.

\subsection{Computational details}

The molecular structure of the GSC has been interpreted theoretically with Gaussian $09 \mathrm{~W}$ package operating at DFT (B3LYP) level of theory with LANL2DZ basis set [13, 14]. The optimized structure of the GSC was visualized by the use of GaussView 5.0 molecular visualization program [15]. The crystal structure geometry of the title compound was taken as the starting structure for gas phase geometry optimization [16]. The LANL2DZ pays a strong attention on transition metals as well as all electron basis sets for all other non-transition metals [14, 17-20]. The optimized geometry structure is shown in Fig. 2. The comparison of selected bond lengths and bonds angles of XRD and optimized geometry is depicted in Table 1. As seen from Table 1, the slight differences in the bond length and bond angles may explain the reason why the intermolecular interactions with surrounding molecules do not exist in gas phase isolated molecule. The Hirshfeld surface analysis was carried out by Crystal Explorer 3.1 program $[21,22]$.

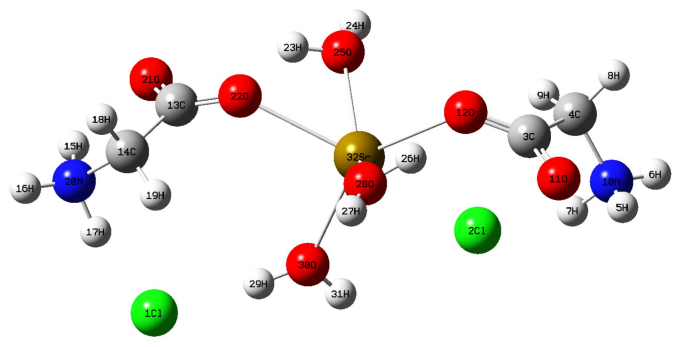

Fig. 2. Optimized geometry of the GSC.

Table 1. Selected bond lengths and bond angles obtained using XRD and optimized geometry.

\begin{tabular}{lcc}
\hline Bond length [A] & XRD [16] & B3LYP/LANL2DZ \\
\hline \hline Sr32-O12 & 2.604 & 2.6368 \\
Sr32-O28 & 2.530 & 2.5355 \\
Sr32-O30 & 2.673 & 2.4931 \\
Sr32-O25 & 2.673 & 2.5419 \\
C3-O12 & 1.271 & 1.2984 \\
C3-O11 & 1.261 & 1.2741 \\
N10-C4 & 1.470 & 1.5175 \\
C4-C3 & 1.515 & 1.5543 \\
Bond angle [ ${ }^{\circ}$ & & \\
C13-O12-Sr32 & 137.57 & 126.027 \\
O12-Sr32-O28 & 74.00 & 59.409 \\
O12-C13-O11 & 123.14 & 127.871 \\
C3-C4-N10 & 112.38 & 104.120
\end{tabular}

\section{Results and discussion}

\subsection{X-ray diffraction analysis}

The preliminary structural analysis of the grown crystal has been carried out by single crystal X-ray diffractometer ENRAF NONIUS CAD4 fitted with MoK $\alpha$ radiation $(\lambda=0.7107 \AA)$. The unit cell parameters are: $\mathrm{a}=16.270 \AA, \mathrm{b}=9.322 \AA$, c $=8.250 \AA, \alpha=\beta=\gamma=90^{\circ}$ and space group $\mathrm{P}_{\mathrm{bcn}}$ is well matched with reported values as depicted in Table 2 [16]. The powder XRD pattern of the 
grown crystal was characterized in the $2 \theta$ range of $5^{\circ}$ to $80^{\circ}$ using Rigaku Miniflex-II diffractometer. The experimental XRD pattern was well matched with simulated pattern XRD pattern and as shown in Fig. 3.

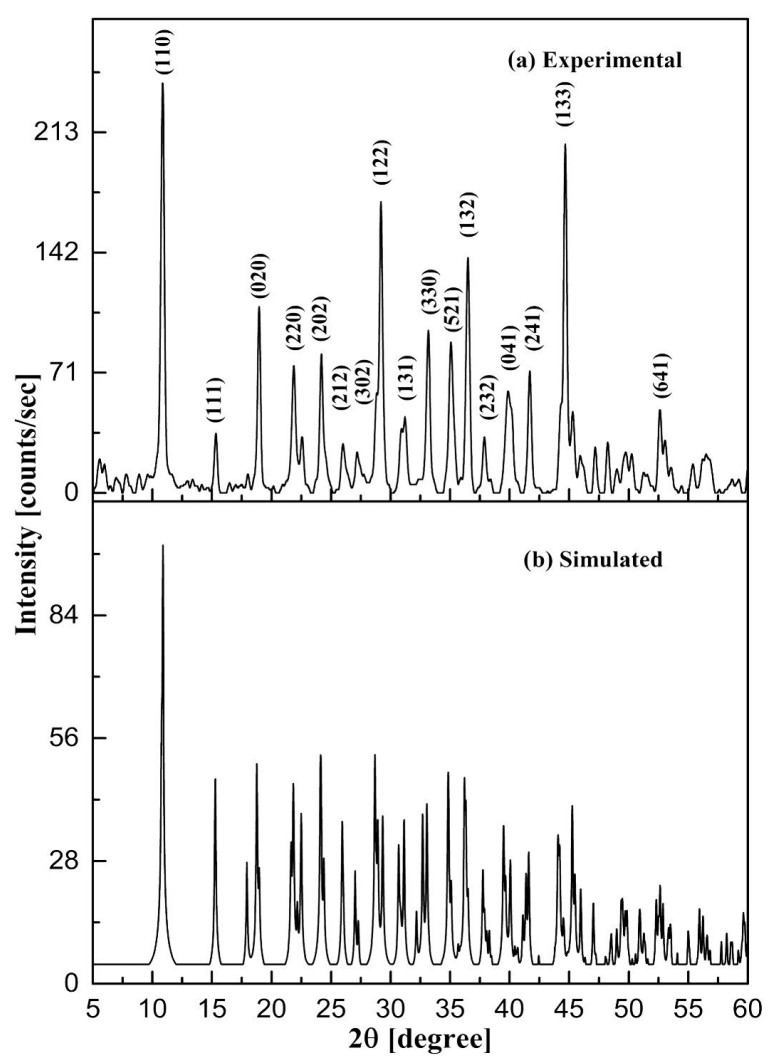

Fig. 3. Powder X-ray diffraction patterns of GSC: (a) experimental; (b) simulated.

\subsection{Vibrational analysis}

The functional groups present in the grown crystal were established by FT-IR analysis. The functional group assignment of the grown crystal has been performed by BRUKER in the range of $4000 \mathrm{~cm}^{-1}$ to $400 \mathrm{~cm}^{-1}$ by $\mathrm{KBr}$ pellet technique. The comparison of theoretical and experimental vibrational spectra is shown in Fig. 4 and the corresponding vibrational group assignments are depicted in Table 3 . The peak at $3428 \mathrm{~cm}^{-1}$ is ascribed to $\mathrm{O}-\mathrm{H}$ asymmetric stretching vibration of the water moiety [23]. The broad envelope peak in $3200 \mathrm{~cm}^{-1}$ to $3050 \mathrm{~cm}^{-1}$ range is due to $\mathrm{NH}_{3}$ asymmetric and symmetric stretching vibrations. The asymmetric and symmetric stretching vibrations of $\mathrm{COO}^{-}$is observed at $1621 \mathrm{~cm}^{-1}$ and $1334 \mathrm{~cm}^{-1}$, respectively. The wavenumber space between them is found to be $287 \mathrm{~cm}^{-1}$, confirming the $\mathrm{COO}^{-}$coordinated to central $\mathrm{Sr}$ ion in the monodentate coordination mode [23-26]. The peaks at $1445 \mathrm{~cm}^{-1}$ and $1415 \mathrm{~cm}^{-1}$ are attributed to in-plane bending vibrations of $\mathrm{OH}$ and $\mathrm{CH}_{2}$, respectively. The out-of-plane bending vibrations of water molecules occurs in wavenumber of $907 \mathrm{~cm}^{-1}$. The stretching vibrations of metal coordinated $\mathrm{O}$ atom is observed at lower region of $514 \mathrm{~cm}^{-1}$, while the corresponding peak in theoretical IR spectrum has been found at $489 \mathrm{~cm}^{-1}$ [4].

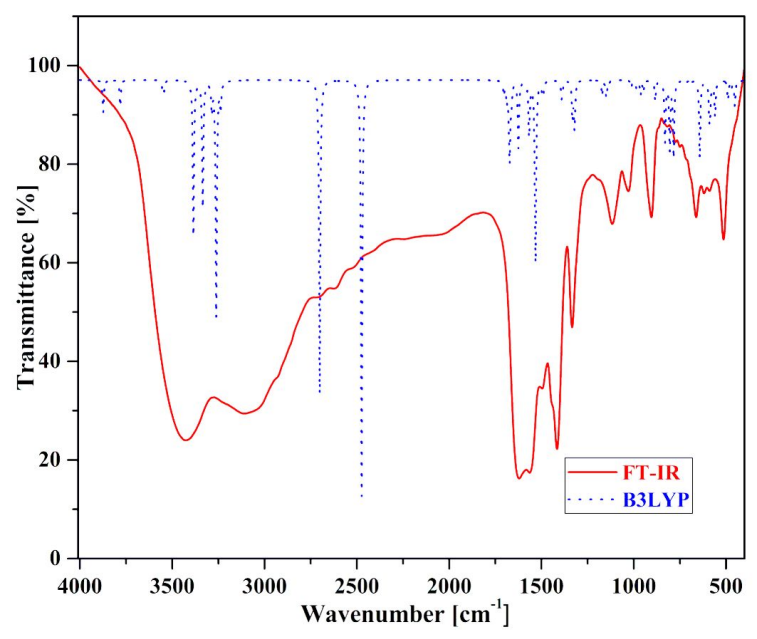

Fig. 4. FT-IR and calculated IR spectra obtained at B3LYP/LANL2DZ level for GSC.

\subsection{Optical studies}

The optical studies of crystals are essential for evaluating the suitability of the material for optoelectronic application. The transmission window of NLO materials is very important because the extraordinary output transmission in most of cases occurs at the UV regions. The optical study of the grown crystal has been carried out by PERKIN LAMDA spectrometer in the range of $190 \mathrm{~nm}$ to $1000 \mathrm{~nm}$. The transmission spectrum is shown in Fig. 5. From the spectrum it is seen that the crystal exhibits $80 \%$ transmission in the entire visible 
Table 2. Comparison of lattice parameters with reported values.

\begin{tabular}{llcc}
\hline & Lattice parameters $[\AA]$ & Crystal system and space group & Volume $\left[\AA^{3}\right]$ \\
\hline \hline Present work & $\mathrm{a}=16.25, \mathrm{~b}=9.33, \mathrm{c}=8.26$ & Orthorhombic, $\mathrm{P}_{\mathrm{bcn}}$ & 1253 \\
Reported work [16] & $\mathrm{a}=16.42, \mathrm{~b}=9.35, \mathrm{c}=8.26$ & Orthorhombic, $\mathrm{P}_{\mathrm{bcn}}$ & 1268 \\
\hline
\end{tabular}

Table 3. Experimental and theoretical vibrational assignments of GSC.

\begin{tabular}{llc}
\hline Assignment & Exp. & B3LYP/LANL2DZ \\
\hline \hline$v_{\text {as }} \mathrm{H}_{2} \mathrm{O}$ & 3428 & 3874 \\
$v_{\mathrm{s}} \mathrm{H}_{2} \mathrm{O}$ & - & 3385 \\
$v_{\text {as }} \mathrm{NH}_{3}$ & 3200 & 3551 \\
$v_{\mathrm{s}} \mathrm{NH}_{3}$ & 3050 & 3237 \\
$v_{\text {as }} \mathrm{CH}_{2}$ & 2923 & 3200 \\
$v_{\mathrm{s}} \mathrm{NH}^{-}$ & 2616 & 2701 \\
$v_{\mathrm{as}} \mathrm{COO}^{-}$ & 1621 & 1672 \\
$\beta\left(\mathrm{NH}_{3}+\mathrm{H}_{2} \mathrm{O}\right)$ & 1562 & 1625 \\
$\beta \mathrm{H}_{2} \mathrm{O}$ & 1445 & 1531 \\
$\beta \mathrm{CH}_{2}$ & 1415 & 1497 \\
$v_{\mathrm{s}} \mathrm{COO}^{-}$ & 1334 & 1332 \\
$\beta \mathrm{CH}$ & 1114 & 1171 \\
$\gamma \mathrm{H}_{2} \mathrm{O}$ & 907 & 883 \\
$\gamma \mathrm{CH}_{2}$ & 662 & 642 \\
$v \mathrm{Sr}-\mathrm{O}$ & 514 & 489 \\
\hline$v: \mathrm{Str}$ & $\beta:$ & \\
\hline
\end{tabular}

$v$ : Stretching, $\beta$ : in-plane bending, $\gamma$ : out-of-plane bending, s: symmetric, as: asymmetric.

region. Such high transmission capability shows that the GSC crystal is suitable for optical applications. The transmission cut off wavelength of the grown crystal is $240 \mathrm{~nm}$ and the bandgap, calculated from the Tauc plot, is $4.5 \mathrm{eV}$ (inset in Fig. 5).

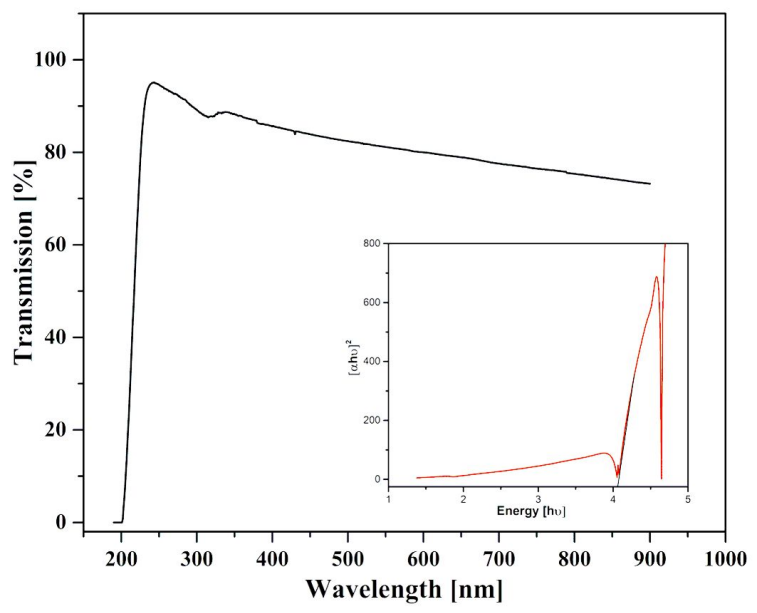

Fig. 5. UV-DRS transmission spectra of GSC crystal and Tauc plot (inset).

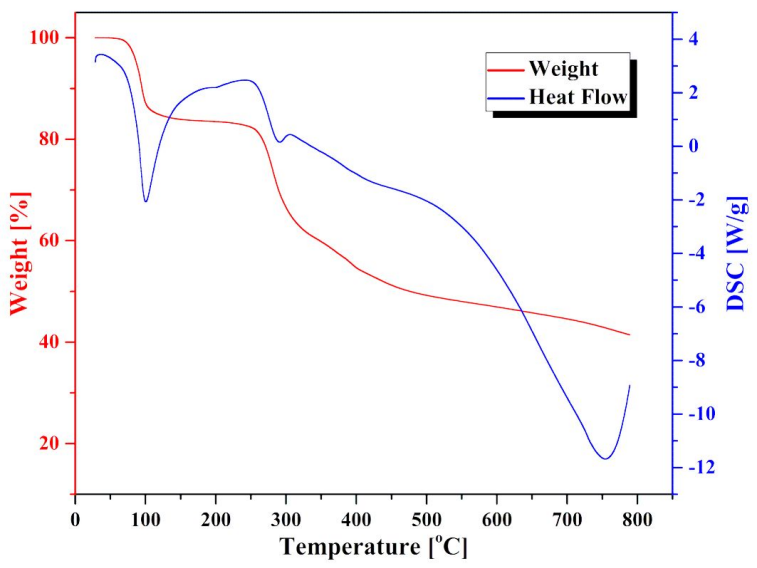

\subsection{TGA/DSC}

Fig. 6. TGA and DSC curves of the GSC crystal.

TGA-DSC curves of an as-grown GSC crystal are shown in Fig. 6. Thermal analysis was carried out by TA SDT Q600 V20.9 Build 20, in temperature range of $30{ }^{\circ} \mathrm{C}$ to $800{ }^{\circ} \mathrm{C}$ at a heating rate of $10{ }^{\circ} \mathrm{C}$ in nitrogen atmosphere. From this analysis, the phase transition and thermal decomposition of the material were evaluated. According to the TGA curve, the material has two decomposition states, as the $18 \%$ first decomposition occurred in $100{ }^{\circ} \mathrm{C}$,

due to trihydrate form of the compound. The major weight loss of $34 \%$ happened in the second stage decomposition due to the decomposition of glycine molecules. The sharp endothermic peak appearing at $100{ }^{\circ} \mathrm{C}$ represents the melting point of the grown crystal. From these results it can be concluded that the material is suitable for practical applications preferably up to $100{ }^{\circ} \mathrm{C}$. 


\subsection{Frontier molecular orbital analysis}

The electronic transition in the GSC crystal was estimated by excitation of electron from the highest occupied molecular orbital to the lowest unoccupied molecular orbital. The electrophilic region has occurred around the chlorine atom, and the nucleophilic zone occurred in the amino group. The HOMO, LUMO and the energy gap of the GSC molecule were calculated on B3LYP/LANL2DZ basis level as shown in Fig. 7. The HOMO denotes a capability to donate an electron (nucleophile) whereas LUMO denotes the ability to obtain an electron. The smaller value of the energy gap depicts the possible charge transfer to occur within the molecule due to the fact that the molecular polarizability became high. From the calculations, HOMO and LUMO of the isolated molecule have been obtained as $-6.0545 \mathrm{eV}$ and $-0.2132 \mathrm{eV}$ and the energy gap of the molecule is $5.8012 \mathrm{eV}$. These values indicate that the compound has high chemical stability.

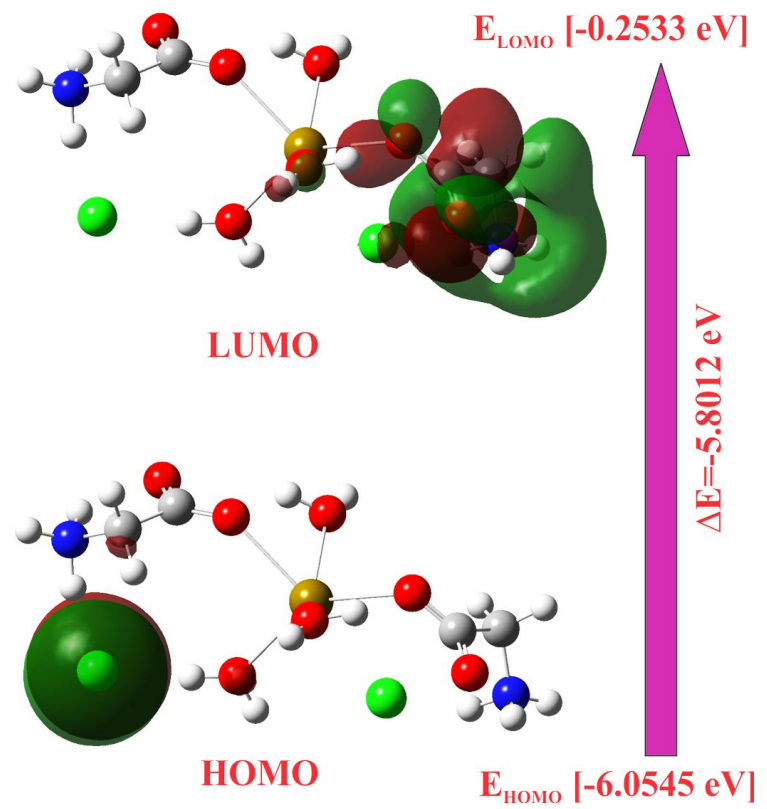

Fig. 7. HOMO and LUMO plots representation of GSC molecule obtained on B3LYP/LANL2DZ level.

\subsection{Hirshfeld surface analysis}

The Hirshfeld surface analysis is an effective way to discern the intermolecular interactions with the crystal surface. The molecular interaction is a superior factor in crystal stability. The crystal packing is mainly caused by the intermolecular interactions. The molecular interactions to be mapped on the surfaces have been shifted in respect to the nearest atom interior and exterior to the Hirshfeld surface. Quantitatively, the contributions of molecular interactions of all the atom are specified by the fingerprint plot as shown in Fig. 8. The metal coordination bond of glycine to strontium ion is the crucial reason for the formation of semiorganic crystal as the strontium ions are extensively bonded with $\mathrm{O}$ atoms of glycine and water molecules present in the crystal. Hydrogen bond interactions are the major contribution $(26.0 \%)$ to Hirshfeld surface due to the amino and water molecule hydrogens. The contribution of chlorine atom is ascribed to the interactions of $\mathrm{Cl}$ atom with $\mathrm{H}$ atoms (14.7\%) of $\mathrm{NH}_{3}$ and water molecules due to van der Waals interactions. The percentage of the contributions in the intermolecular and intramolecular interactions have been quantified (Fig. 10) and displayed as a pie chart in Fig. 9.

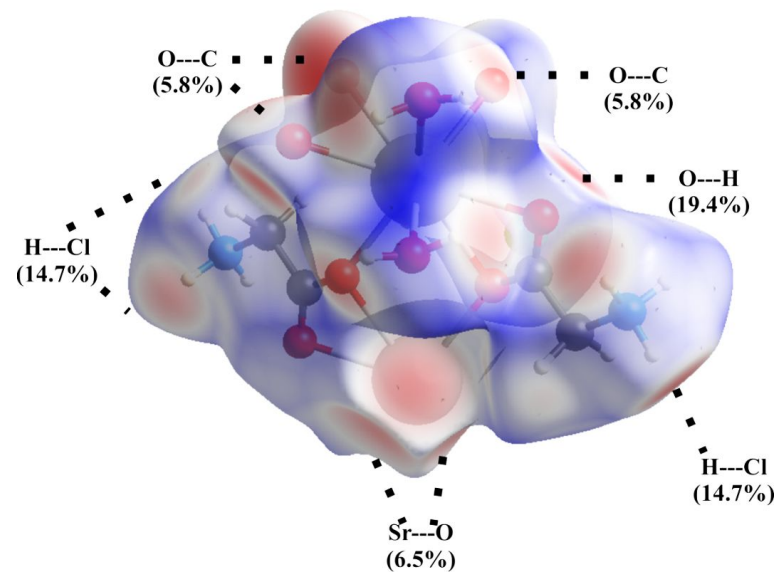

Fig. 8. Hirshfeld surface map of GSC.

\subsection{NLO properties}

The NLO properties of a molecule primarily depend on the dipole-dipole interactions, weak intermolecular bonding, such as hydrogen bonds and van der Waals bonds. Characteristically, the organic molecules have higher nonlinearity owing to 

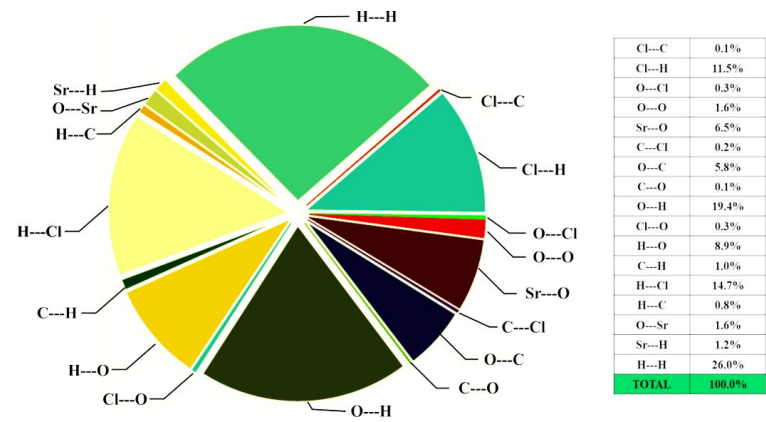

Fig. 9. Pie chart of atom to atom intermolecular interactions.

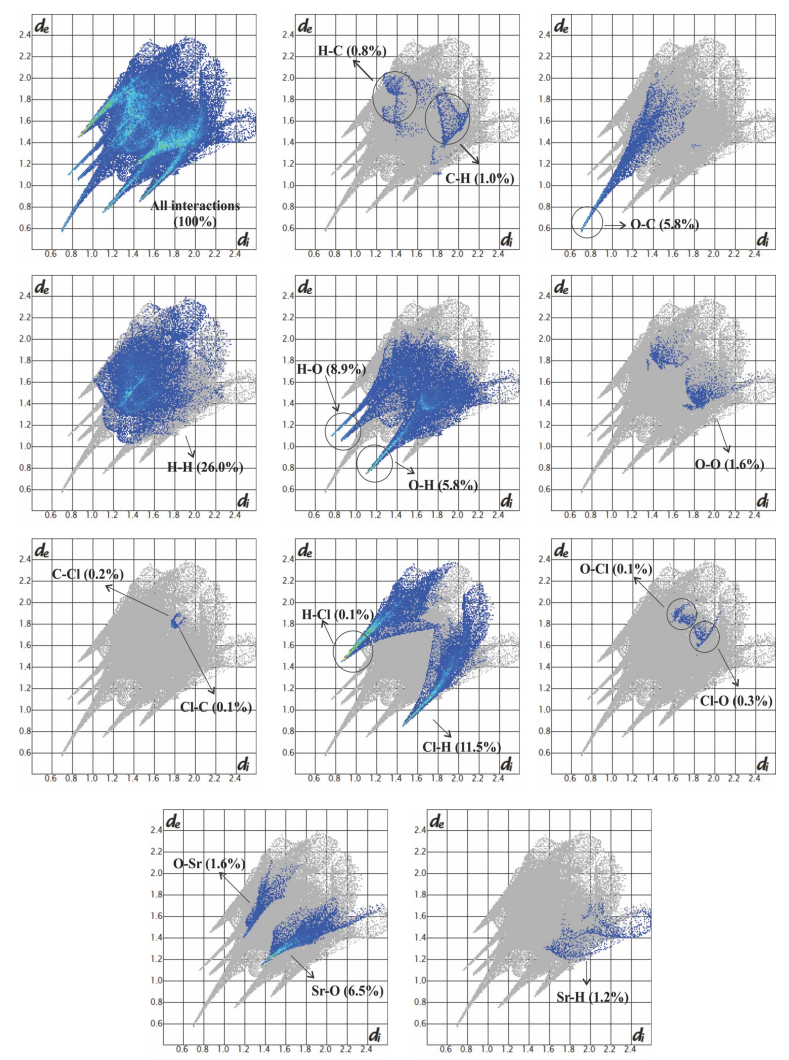

Fig. 10. Fingerprint plots of GSC.

the conjugated interactions of molecules. In the finite field approach, the molecule is in the presence of a static electric field [27]. The levels of higherorder polarizability were computed from the finite field approach, such as the molecule surrounded by a static electric field. The small energy gap difference of HOMO and LUMO manifested that the charge transfer takes place within the molecule through the metal coordination and as a result, the nonlinear optical response is increased. The first order hyperpolarizability having 27 tensor components can be minimized to 10 through Kleinman symmetry (Table 4 ). The polarizability and hyperpolarizability components were obtained from the frequency calculation by the B3LYP/LANL2DZ theory. The total dipole moment, linear polarizability and first-order hyperpolarizability were estimated from the subsequent relations:

$$
\begin{gathered}
\mu_{\text {total }}=\left(\mu_{x}+\mu_{y}+\mu_{z}\right)^{\frac{1}{2}} \\
\alpha_{\text {total }}=\frac{1}{3}\left(\alpha_{x x}+\alpha_{y y}+\alpha_{z z}\right) \\
\beta_{\text {total }}=\left[\left(\beta_{x x x}+\beta_{x y y}+\beta_{x z z}\right)^{2}+\left(\beta_{y y y}+\beta_{y z z}+\beta_{y x x}\right)^{2}\right. \\
\left.+\left(\beta_{z z z}+\beta_{z x x}+\beta_{z y y}\right)^{2}\right]^{\frac{1}{2}}
\end{gathered}
$$

The calculated dipole moment, polarizability and first order hyperpolarizability of GSC are $6.421 \mathrm{D},-110.235 \times 10^{-24}$ esu and $1.734 \times$ $10^{-30}$ esu, respectively. The first order hyperpolarizability of the title compound is 13 times higher than that of standard organic NLO material urea $\left(0.13 \times 10^{-30} \mathrm{esu}\right)$.

\section{Conclusions}

We have successfully grown the transparent single crystal of GSC using slow evaporation technique. The grown crystal was subjected to single crystal and powder X-ray diffraction analyses to evaluate its structure. The lattice parameters were well matched with reported values. Additionally, the grown crystal was subjected to FT-IR investigation, to find the molecular functional groups present in the crystal. The optical properties of the grown crystal were assessed with the help of UVDRS spectrometer. The transparency of the crystal was nearly $80 \%$, and the calculated band gap was $4.5 \mathrm{eV}$. The molecular packing interactions were examined by Hirshfeld surface analysis and it was stated that the molecular cohesion of $\mathrm{N}-\mathrm{H} \cdots \mathrm{Cl}$, 
Table 4. The calculated values of dipole moment, polarizability $\left[\alpha \times 10^{-24} \mathrm{esu}\right]$ and hyperpolarizability $[\beta \times$ $\left.10^{-30} \mathrm{esu}\right]$ along with the individual tensor components of GSC.

\begin{tabular}{cccccc}
\hline Components & Calc. value a.u. & $\begin{array}{c}\text { Calc. value } \\
\text { esu }\end{array}$ & Components & $\begin{array}{c}\text { Calc. value } \\
\text { a.u. }\end{array}$ & Calc. value esu \\
\hline \hline$\mu_{\mathrm{x}}$ & $3.9967 \mathrm{D}$ & - & $\beta_{\mathrm{xxx}}$ & 79.0544 & 0.6829 \\
$\mu_{\mathrm{y}}$ & $-5.0139 \mathrm{D}$ & - & $\beta_{\mathrm{xxy}}$ & -62.8121 & -0.5427 \\
$\mu_{\mathrm{z}}$ & $0.3528 \mathrm{D}$ & - & $\beta_{\mathrm{xyy}}$ & 68.6617 & 0.5939 \\
$\mu_{\mathrm{total}}$ & $6.4216 \mathrm{D}$ & - & $\beta_{\mathrm{yyy}}$ & -33.0811 & -0.2858 \\
$\alpha_{\mathrm{xx}}$ & -67.8773 & -10.0594 & $\beta_{\mathrm{xxz}}$ & -60.9527 & -0.5266 \\
$\alpha_{\mathrm{xy}}$ & 21.581 & -3.1983 & $\beta_{\mathrm{xyz}}$ & -43.5385 & -0.3761 \\
$\alpha_{\mathrm{yy}}$ & -144.6154 & -21.4320 & $\beta_{\mathrm{yyz}}$ & 6.3488 & 0.0549 \\
$\alpha_{\mathrm{xz}}$ & 29.8959 & 4.4306 & $\beta_{\mathrm{xzz}}$ & -4.613 & -0.0399 \\
$\alpha_{\mathrm{zz}}$ & -118.213 & -17.5192 & $\beta_{\mathrm{yzz}}$ & -26.2106 & -0.2264 \\
$\alpha_{\mathrm{yz}}$ & -0.2543 & -0.0377 & $\beta_{\mathrm{zzz}}$ & -15.3876 & -0.1329 \\
$\alpha_{\mathrm{total}}$ & -110.2352 & -16.3369 & $\beta_{\mathrm{total}}$ & 365.5498 & 1.7340 \\
\hline
\end{tabular}

For $\alpha, 1$ a.u. $=0.1482 \times 10^{-24}$ esu, for $\beta, 1$ a.u. $=0.008629 \times 10^{-30}$ esu, calc. value of $\mu_{\text {urea }}=1.3732$ $\mathrm{D}$ and $\beta_{\text {urea }}=0.3728 \times 10^{-30}$ esu.

$\mathrm{Sr}-\mathrm{O} \cdots \mathrm{C}, \mathrm{O}-\mathrm{H} \cdots \mathrm{Cl}$, and $\mathrm{H} \cdots \mathrm{H}$ intermolecular interactions were responsible for crystal packing arrangements. The percentages of molecular interactions in the crystal packing were examined by fingerprint plots. The intramolecular charge transfers in the crystal were illustrated by the frontier molecular orbital analysis. The lower energy gap implies that the metal coordination bond acts like a bridge for intramolecular charge transfer. The calculated value of first order hyperpolarizability of the molecule is 13 times higher than that of urea; it shows the nonlinear activity of the crystal.

\section{References}

[1] Williams D.J., Nonlinear Optical effects in molecules and polymers, Wiley, New York, 1991.

[2] Chemla D.S., ZYss J., 1987 Nonlinear Optical Properties of Organic Molecules and Crystals, Academic Press, New York, 1987.

[3] Long N.J., Angew. Chemie Int. Ed. English, 34 (1995), 21.

[4] Ghazaryan V.V., Fleck M., Petrosyan A.M., $J$. Mol. Struct., 977 (2010), 117.

[5] Müller G., Maier G.M., Lutz M., Inorganica Chim. Acta, 218 (1994), 121.

[6] Balakrishnan T., Ramamurthi K., Mater. Lett., 62 (2008), 65.

[7] Marudhu G., Krishnan S., Thilak T., Samuel P., Vinitha G., Pasupathi G., J. Nonlinear Opt. Phys. Mater., 22 (2013), 1350043.

[8] Natarajan S., Muthukrishnan C., Bahadur S.A., RaJARAM R.K., RAJAN S.S., Z. Krist. - New Cryst. Struct., 198 (1992) 265.
[9] Lenin M., Bhavannarayana G., Ramasamy P., Opt. Commun., 282 (2009) 1202.

[10] Riscob B., Shakir M., Ganesh V., Vijayan N., Wahab M.A., Bhagavannarayana G., J. Therm. Anal. Calorim., 110 (2012) 1225.

[11] Narayana Moolya B., Darmaprakash S.M., $J$. Cryst. Growth, 293 (2006), 86.

[12] Uma B., Rajnikant, Murugesan K.S., Krishnan S., BoAz B.M., Prog. Nat. Sci. Mater. Int., 24 (2014), 378.

[13] Frisch M.J., TruCKS G.W., SCHLEgel H.B., Scuseria G.E., RobB M.A., Cheeseman J.R., Scalmani G., Barone V., Mennucci B., PeTersson G.A., Nakatsuji H., Caricato M., Li X., Hratchian H.P., Izmaylov A.F., Bloino J., Zheng G., Sonnenberg J.L., HadA M., Ehara M., TOYota K., FuKuda R., Hasegawa J., IshidA M., Nakajima T., Honda Y., Kitao O., Nakai H., VReven T., Montgomery-JR J.A., Peralta J.E., Ogliaro F., BeArpark M., Heyd J.J., BrothERs E., Kudin KN., Staroverov V.N,. Keith T., Kobayashi R., Normand J., RaghaVachari K., Rendell A., Burant J.C., IYEngar S.S., TOMASI J., Cossi M., Rega N., Millam J.M., Klene M., Knox JE., Cross J.B., BAKKen V., AdAMo C., JARAMillo J., Gomperts R., StratmanN R.E., Yazyev O., Austin A.J., CAmmi R., Pomelli C., OCHTERSKi J., W, MARTIN R.L., MOROKUMA K., ZAKRZEWSKI V.G., VOTH G.A., SALVADOR P., DANNENBERG J.J., DAPPRICH S., DANIELS A.D, FARKAS O., Foresman J.B., Ortiz J.V., Cioslowski J. FoX D.J., Gaussian 09, Rev A.02, Gaussian, Inc., Wallingford CT, 2010.

[14] Ben Nasr M., Soudani S., Lefebvre F., Jelsch C., Ben NASR C, J. Mol. Struct., 1138 (2017), 71. 
[15] Frisch A., Nielson A.B., Holder A.J., GAUSSVIEW User, Manual Gaussian Inc. Pittsburgh, 2000.

[16] Narayanan P., Venkataraman S., Z. Krist. - Cryst. Mater., 142 (1975), 52.

[17] Sethuraman K., Ramesh Babu R., GopalakrIShnan R., RAMASAmy P., Cryst. Growth Des., 8 (2008), 1863.

[18] Rajasekar M., Muthu K., Aditya Prasad A., MeEnaKshisundaram S.P., J. Mol. Struct., 1085 (2015), 147.

[19] Tounsi A., Elleuch S., Hamdi B., Zouari R., Salah A.Ben., J. Mol. Struct., 1141 (2017), 512.

[20] Muthu K., Meenatchi V., Rajasekar M., Aditya Prasad A., Meena K., Agilandeshwari R., Kanagarajan V., Meenakshisundaram S., J. Mol. Struct., 1091 (2015), 210.

[21] Turner M.J., McKinnon J.J., WolfF S.K., GrimWOOD D.J., SPACKMAN P.R., JAYATILAKA D., SPACKMAN M.A., Crystal Explorer17, Univ. West. Aust., 2017.
[22] Spackman M.A., Jayatilaka D., CrystEngComm., 11 (2009), 19.

[23] TAMER Ö., J. Mol. Struct., 1144 (2017), 370.

[24] Heren Z., PaşaoĞlu H., Kaştaş G., Keser C., Yeşilel O.Z., BÜYÜKGÜngÖR O., Z. Anorg. Allg. Chemie, 632 (2006), 1578.

[25] TAMER Ö., TAMER S.A., İdIL Ö., AVCI D., Vural H., Atalay Y., J. Mol. Struct., 1152 (2018), 399.

[26] Tamer Ö., AvCi D., Atalay Y., J. Inorg. Organomet. Polym. Mater, 27 (2017), 700.

[27] Kurtz H.A., Stewart J.J.P., Dieter K.M., J. Comput. Chem., 11 (1990), 82.

Received 2018-03-09

Accepted 2019-04-23 